\title{
Short-Term Isolation Increases Social Interactions of Male Rats: A Parametric Analysis
}

\author{
RAYMOND J. M. NIESINK AND JAN M. VAN REE ${ }^{1}$ \\ Rudolf Magnus Institute for Pharmacology, University of Utrecht, Medical Faculty \\ Vondellaan 6, 3521 GD Utrecht, The Netherlands
}

Received 19 March 1982

\begin{abstract}
NIESINK, R. J. M. AND J. M. VAN REE. Short-term isolation increases social interactions of male rats: $A$ parametric analysis. PHYSIOL. BEHAV. 29(5) 819-825, 1982.-Frequencies of social interactions were higher in pairs of short-term individually housed male Wistar rats as compared to group-housed animals. This was most pronounced when an individually housed rat and a group-housed conspecific were tested together in the morning under red light conditions. Then, in particular the behavioral elements exploration partner, anogenital investigation, crawl over/mount and social grooming were enhanced. The increases in social interactions was dependent on the duration of the period of individual housing and appeared to be maximal after 4 to 7 days of individual housing. The effect extinguished after repeated testing. The observed behavioral changes were hardly affected by habituation to the test cage and were also present in young animals. The increase in social interactions is apparently not due to a general increase in locomotor or exploratory behavior, since no differences in ambulation between individually- and group-housed animals were observed when they were tested together in the social interaction test, and locomotor activities hardly differed in an open field test procedure.
\end{abstract}

Social interaction Housing conditions Social isolation Light conditions Social behavior

STUDIES dealing with individually housed animals as compared to group-housed conspecifics have been performed, using a variety of laboratory animals like dogs, mice, rats and monkeys $[2,8,17,19]$. Besides changes in neurochemistry [27], physiology [4] and anatomy [32], individual housing causes differences in behavior of rats, such as hyperlocomotion $[13,14,31]$, increased aggressive behavior [29], facilitated acquisition and delayed extinction of shuttlebox avoidance responses [21]. However, the direction and significance of some of these behavioral and physiological parameters have been a matter of debate. Thus, DalrympleAlford and Benton [5,6] showed an initial reduced locomotor activity of isolated rats, while other investigators reported an increased activity only [14].

In most of these studies long-term individually housed animals were used and the differences with group-housed animals were apparent only after weeks or sometimes even months of individual housing. However, other studies showed that also short-term social deprivation induces disturbances, for instance, a delayed ddaptation to painful stimuli when rats were repeatedly tested on a hotplate (Van Ree, unpublished observations), an increase in systolic blood pressure and heart rate [12] and increased social activity when the rats were put back in a social situation $[11,20$, 28].

In the present study we have studied in detail the increas- ing effect of short-term isolation on social interactions of pairs of rats. Additional experiments showed that this effect is specific for social interactions and is not due to a more general change in locomotion or exploratory behavior of isolated rats.

\section{METHOD}

\section{Animals}

Male rats of a Wistar strain, weighing between 180 and 220 grams were used, unless otherwise indicated (see experiment $d$ below). The rats were obtained from TNO-Zeist, The Netherlands and housed in wire cages in groups of approximately 20 animals. Prior to experimentation the rats were either individually housed (isolated, I) or in groups of 5 animals per cage (non-isolated, $S$ ) for 7 days, except as otherwise indicated. Home cages were of plastic, $22 \times 13 \mathrm{~cm}$ and $26 \times 40 \mathrm{~cm}$, respectively. During the isolation period the cages of isolated and non-isolated rats were in the same room, so the isolated animals could hear and probably smell other rats, but did not have physical contact with them. During this period the animals were kept in a temperature controlled environment $\left(25 \pm 1^{\circ} \mathrm{C}\right)$ with a regular day/night cycle (20-100 lux; lights on 7:00 a.m. to 7:00 p.m.). Standard food and tap water were available ad lib. Animals were used only once, except otherwise indicated.

'Requests for reprints should be sent to Dr. J. M. van Ree at the above address. 


\section{Open Field Behavior}

Open field behavior was analyzed in a circular arena as described in detail elsewhere [33]. Ambulation (number of floor units crossed), rearing (facing the wall and in the middle), grooming and defecation were measured for 5 minutes in 7-day isolated (I) and group-housed (S) animals. Ambulation was recorded per minute, other items were recorded per 5 minutes. The same animals were repeatedly tested with intervals of 2.5 hours, starting at $9 \mathrm{a} . \mathrm{m}$.

\section{Test Procedure for Social Interactions}

Rats were tested for social interactions with a naive test partner. The body weights of the 2 rats did not differ more than 10 grams. The rats were weighed at the start of the isolation period and on the day of testing. On the day before testing they were marked. The tests were carried out between 9:00 a.m. and 1:00 p.m. (except in eperiment $a$ ). The 2 rats were placed in a perspex observation cage $(70 \times 70 \times 50$ $\mathrm{cm}, 1 \times w \times h)$. The floor and back of the cage were of a green color, the other walls were transparent. The floor was divided into 16 squares by painted lines. At the end of each session the boluses were removed and the floor and walls were cleaned. Two red light bulbs of 60 watts each, situated $70 \mathrm{~cm}$ above the floor of the cage and covered with white paper, served as light source. Each test session lasted 10 minutes and the behaviors of the rats were recorded on video tape (Sony U-Matic) using a camera with a silicone target tube which is extremely sensitive to red light. Time was recorded synchronically. Neither the experimenter nor other rats were present in the test room during the test trial; besides the camera, video equipment was in an adjacent room. The social interactions of the animal were analyzed blindly after the test sessions by observing the recordings twice, once for each animal. The set of recorded elements of behavior was similar to that described by Grant [16]; however, some elements did not occur, and others occurred too infrequently to allow a separate statistical analysis and therefore they were combined. Thus the social interactions were divided among the following $\mathbf{8}$ different items:

Exploration of the partner. Sniffing or licking any part of the body of the conspecific except the anogenital area.

Anogenital investigation. Sniffing or licking the anogenital area of the other rat.

Crawl over/mounting. The rat stands on its hind legs and puts one or both forepaws on the partners back, or climbs over the partner, the partner is enclosed in the flanks, the anterior part of the mounting rat rests on the hind-quarter of the partner and the rat sometimes performs vibrating movements.

Social grooming. The rat licks and chews the fur of the conspecific, while placing its forepaws on the back or the neck of the other rat. Sometimes this occurs in a very rude fashion (aggressive grooming).

Biting. The rat bites by fast snapping and leaving off again, as well as by holding on while jerking.

Approachinglfollowing. Walking or running in the direction of the partner, which stays where it is or moves away.

Kicking. The rat kicks backwards at the conspecific with one or both hindlegs.

Fighting. All aggressive behaviors towards the partner, like boxing, sideways attack, etc.

The frequencies of these different elements were counted per minute. If a certain behavior exceeded 5 seconds, it was counted each 5 th second again. As a measure of the total amount of social interactions of one animal the sum of the different items per 10 minutes was taken. In one experiment ambulation (number of floor units crossed), rearing (middle and wall) and self-grooming activities during the social interaction period were measured. In another experiment total time $(\mathrm{sec})$ in which a rat was in physical contact with its partner (except tail-tail contact) was compared to that of the total frequency of social interactions. In the first two experiments 2 non-isolated rats (S-S), a non-isolated and an isolated rat (S-I) and 2 isolated rats (I-I) were tested together; in the other experiments a non-isolated and an isolated rat ( $\mathrm{S}-\mathrm{I})$ were tested together.

\section{Effect of Different Variables on Social Interactions}

a. Light condition and time of day. In the first condition two white light bulbs of 75 watts situated approximately 70 $\mathrm{cm}$ above the floor of the observation cage were used as a light source. In the second (and all the other situations) two red light bulbs as described above were used. Light intensity was 460 and 0.4 lux, respectively. The tests were performed at different times of the day i.e., from 9:00 a.m. to 1:00 p.m. and from 7:00 p.m. to $10: 30$ p.m. In these experiments the isolation period was 4 days.

$b$. Habituation to the observation cage. Habituation was performed by placing the rats alone in the observation cage for 10 minutes on the two days before the test. The following four pairs of rats were tested:

$$
\begin{array}{ll}
S_{\text {hab }} & -I_{\text {hab }} \\
S_{\text {non-hab }} & -I_{\text {non-hab }} \\
S_{\text {non-hab }} & -I_{\text {hab }} \\
S_{\text {hab }} & -I_{\text {non-hab }}
\end{array}
$$

(hab = habituated to the test cage; non-hab $=$ not habituated to the test cage)

c. Duration of social deprivation and effect of repeated testing. Experiments were performed in which the duration of social deprivation of the isolated rats was varied. Rats were tested after $1,4,7$ or 28 days of social isolation with a group-housed partner. The rats which were tested after 7 days of isolation were tested again on the two days following the first interaction test with the same partner. The rats were put back in their home cages immediately after testing.

d. Age of the rats. Social interactions were measured in pairs of rats that were 4-week-old (weighing \pm 120 grams) and compared to those of 8-week-old rats (weighing \pm 200 grams). Half of the animals were individually housed for 7 days and the others in groups of 5 animals, starting 1 week before the test.

\section{Statistical Analyses}

For most of the variables a Wilk-Shapiro test for normality on the data indicated that the underlying population did not deviate from a normal distribution [26], here parametric statistical methods, otherwise non-parametric statistical tests were used. Differences between the two means were tested with Student $t$-tests or Mann Whitney-U-tests. Testing of more samples that were obtained at the same time was performed with a one-way analysis of variance, or when more than one factor at the same time had to be compared (e.g., housing condition versus time of testing) a two-way analysis of variance with repeated measures [25] was used. 

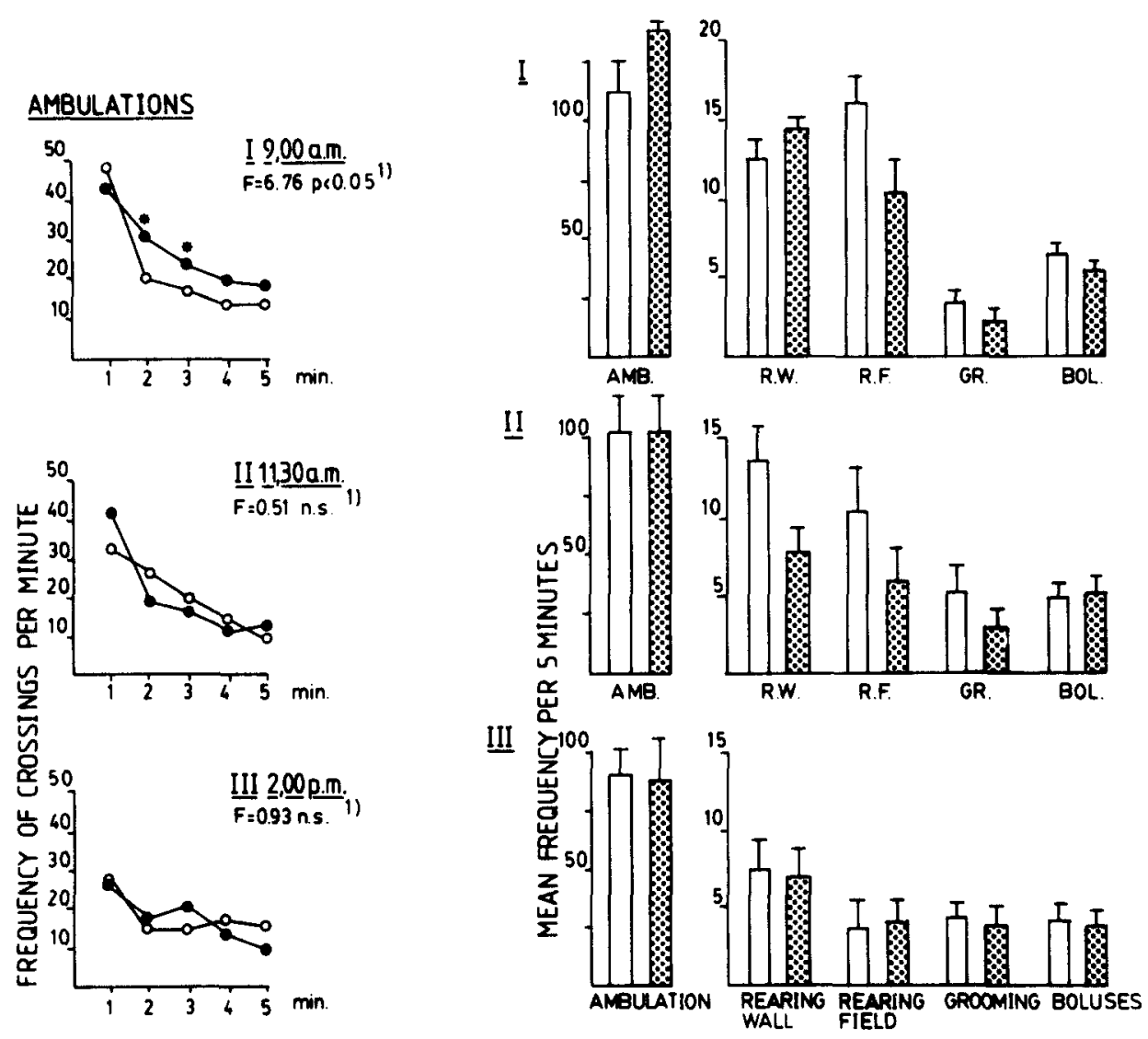

A

$\underline{B}$

FIG. 1. Open field behavior of 7-day isolated (closed circle, shaded columns; $n=6$ ) and group-housed (open circle, open columns; $n=6$ ) animals in 3 subsequent trials (I, II, III). The intertrial interval was 2.5 hours. (A) Ambulation score versus minute of testing. (B) Ambulation, rearing (field and wall), self-grooming and boluses per 5 minutes. Data are expressed as mean score, vertical bar indicates S.E.M. " Two way analysis of variance with replications. ${ }^{*} p<0.05$ (Student's $t$-test).

\section{RESULTS}

Body weights were not affected by the 7-day isolation procedure. During this time period the body weights of S-rats gained from $199.2 \pm 2.6$ on day 1 to $225.1 \pm 2.2$ on day 8 (mean \pm S.E.M., $\mathrm{n}=25$ ); those of the $\mathrm{I}$-animals from $199.0 \pm 2.2$ to $227.3 \pm 2.0(n=25)$. In the open field test a difference in ambulation between 7-day isolated and grouphoused animals within the first trial was observed, but not in the 2nd or 3rd trial (Fig. 1A). In fact a higher number of ambulations was observed in the I-rats as compared to the S-rats during the 2nd and 3rd minute of the 1st test trial; this effect may be due to a diminished decrease of ambulation over time in the I-rats. No differences were found in ambulations per 5 minutes between I- and S-animals, nor in any of the other measures of the open field test (Fig. 1B).

The distribution of the different items of the social interactions is given in Table 1. Generally the tested rats were not very aggressive and most of the observed items can be considered amicable exploratory behavior. The most frequently observed item was exploration of the partner. Isolation increased the total amount of social interactions when the partner was a group-housed animal as well as when it was another isolated rat. Comparing the different items in the I-I pairs with those in the S-S pairs, significant increases in anogenital investigation, social grooming, approach/follow, kicking and fighting were found. Ambulation during the social interaction period was increased in the isolated animals, while rearing wall and field were decreased. When isolated animals were tested with non-isolated rats as their partner, exploration of the partner, anogenital investigation, mounting/crawl over, and social grooming were increased when compared to the group-housed test partners. Rearing of the I-animals was less than that of the S-animals, while no difference was present in the ambulation of the rats. Comparing the behavioral items of group-housed animals tested with isolated partners (S-I) with those of group-housed animals tested with group-housed partners (S-S), a decrease in anogenital investigation $(p<0.05)$, and an increase in ambulation and rearing field $(p<0.01$ and $p<0.001$, respectively) was observed in the first mentioned animals. When the items of isolated animals in the test with group-housed partners (I-S) were compared with those of isolated animals from the test with isolated partners (I-I), a significant increase in rearing field $(p<0.05)$ was found; although the different items were not significantly higher, in the latter (I-I) situation more 
TABLE 1

EFFECT OF SOCIAL DEPRIVATION ON SOCIAL INTERACTIONS

\begin{tabular}{|c|c|c|c|c|c|c|c|}
\hline Behavioral Item & $\mathbf{S}-\mathbf{S}$ & $\mathrm{I}-\mathrm{I}$ & $\Delta \mathrm{I}-\mathrm{S}$ & \multicolumn{3}{|c|}{ S-I } & $\Delta 1-\mathrm{S}$ \\
\hline Exploration Partner & $18.5 \pm 1.3$ & $18.3 \pm 1.7$ & n.s. $\dagger$ & $15.4 \pm 0.8$ & $-21.2 \pm$ & 0.8 & $p<0.001 \ddagger$ \\
\hline Anogenital Investigation & $6.2 \pm 0.9$ & $10.6 \pm 1.3$ & $p<0.02$ & $2.9 \pm 0.8$ & $7.0 \pm$ & 1.0 & $p<0.01$ \\
\hline Crawl Over/Mount & $2.0 \pm 0.4$ & $4.2 \pm 1.1$ & n.s. & $1.3 \pm 0.5$ & $6.6 \pm$ & 1.0 & $p<0.001$ \\
\hline Social Grooming & $1.8 \pm 0.5$ & $7.5 \pm 1.7$ & $p<0.01$ & $2.4 \pm 0.6$ & $6.7 \pm$ & 1.0 & $p<0.002$ \\
\hline Biting* & 0 & 1 & n.s. & 0 & 0 & & n.s. \\
\hline Approach/Follows & $3.6 \pm 0.7$ & $7.8 \pm 1.2$ & $p<0.01$ & $3.5 \pm 1.0$ & $5.4 \pm$ & 0.8 & n.s. \\
\hline Kicking* & 0 & 2 & $p<0.02$ & 0 & 0 & & n.s. \\
\hline Fighting* & 0 & 4 & $p<0.002$ & 0 & 0 & & n.s. \\
\hline $\begin{array}{l}\text { Total Amount of Social } \\
\text { Interactions }\end{array}$ & $32.9 \pm 4.2$ & $58 . \overline{7} \pm 3.0$ & $p<0.001$ & $27.0 \pm 2.6$ & $-\overline{50.7 \pm}$ & 2.0 & $p<0.001$ \\
\hline Ambulations & $221.5 \pm 9.6$ & $259.3 \pm 11.8$ & $p<0.05$ & $281.1 \pm 19.8$ & $-299.5 \pm$ & 29.9 & n.s. \\
\hline Rearing, wall & $41.5 \pm 3.6$ & $30.3 \pm 2.5$ & $p<0.02$ & $41.0 \pm 1.8$ & $-33.3 \pm$ & 4.1 & n.s. \\
\hline Rearing, field & $27.3 \pm 2.2$ & $14.6 \pm 1.6$ & $p<0.001$ & $36.0 \pm 3.3$ & $-\quad 20.7 \pm$ & 1.4 & $p<0.001$ \\
\hline Self-Grooming & $7.3 \pm 1.2$ & $6.6 \pm 1.2$ & n.s. & $4.3 \pm 1.3$ & $3.3 \pm$ & 1.7 & n.s. \\
\hline
\end{tabular}

Contribution of the various analysed items to the total amount of social interactions in 3 experiments in which 7 -day isolated animals (I) were tested with other I animals (I-I) or with group-housed animals (I-S) and group-housed animals (S) with other group-housed animals (S-S)

In addition ambulations, rearing (field and wall) and self-grooming are presented (lower part of the table). Data of 12 observations are given as the mean ( \pm S.E.M.) or median $\left(^{*}\right)$ frequency that a certain item occurred in the 10 -minute test session.

†Difference between I- and S-anmals from test pairs with a partner with the same housing background.

$\ddagger$ Idem with test partner from different housing condition.

Statistical analysis was performed using Student's $t$-test or Mann-Whitney U test.

aggressive-like behavior occurred (kicking, biting and fighting). Figure 2 presents the frequency of social interactions per 2 minutes. A difference between the four tested groups was observed, $F=34.13, p<0.01$. Frequency of social interactions increased more over time for I-animals than for $\mathrm{S}$-animals. In fact, this difference was present between the two tests in which partners from the same housing conditions were tested (I-I versus S-S), $\mathrm{F}=38.57, p<0.002$, and also between the I- and S-animals in the I-S encounters, $F=50.77$, $p<0.01$. There was a small difference between the $S$-animals from the two different test conditions (S-S versus S-I), $\mathrm{F}=4.96, p<0.05$, but not between the I-animals from the two test conditions. Repeated scoring of the same animals from the same tape (by the same observer) never gave deviations of more than $5 \%$, indicating that the used procedure is rather reproducable.

Figure 3 shows a correlation diagram of duration and frequency of social interactions of 7-day isolated rats (I) in a dyadic encounter of 10 minutes with S-rats. The correlation appeared to be highly significant.

\section{Influence of Different Variables}

a. Light condition and time of day. Table 2 shows the data obtained in the social interaction test under different test conditions. Testing under red light caused a slight increase of the total amount of social interactions of the S-rats. Testing in the evening (dark period) further increased the total amount of social interactions in these animals. The social interactions in the I-animals were hardly affected by both test conditions. The difference in total amount of social interactions between I- and S-rats, if tested together, was highest when tested under red light in the morning $(p \leqslant 0.002)$. b. Habituation to the test cage. Habituation to the test cage hardly influenced the total amount of social interactions of the S- or the I-rats (Table 3). In all 4 tests significant differences were observed between I- and S-animals, $\mathrm{F}(1.32)=44.89 p \leqslant 0.001$, but not between the habituation conditions, $F(3.32)=0.36$, n.s.

c. Duration of social deprivation and effect of repeated testing. Already after one day of social isolation a difference in total amount of social interactions of the I-rat as compared to the S-rat was observed (Table $4 a$ ). This difference increased and was highly significant after 4 days of isolation and did not further increase by prolongation of the isolation period to 7 or 28 days. Repeated testing of the 7-day isolated animals on the 8th and 9th day of their isolation period with the same partner resulted in a gradual decrease in the difference of the social interactions between the I- and S-rats (Table $4 b$ ). This decrease is mainly due to a diminished amount of social interactions of the I-rats. The contribution of the different items to the total frequency of social behaviors was influenced neither by the duration of the isolation period nor by extinction of the increase in social activity in the isolated rats.

d. Animals of different age. Younger animals also showed behavioral changes after a 7-day isolation period. Table 5 compares the social interactions between younger animals and older ones ( 4 and 8 weeks, respectively, at the time of testing). Younger animals were physically more active; they mounted, crawled and climbed more on their partners than older conspecifics, both in the group-housed and the isolated animals. Differences between the 4 and 8-week old grouphoused rats were found in exploration partner/anogenital investigation $(p<0.01)$, mounting/social grooming $(p<0.01)$, follow/approach $(p<0.05)$ and total amount of social interactions $(p<0.05)$. Follow/approach was significantly different between 4 - and 8-week old isolated rats $(p<0.05)$. Explora- 


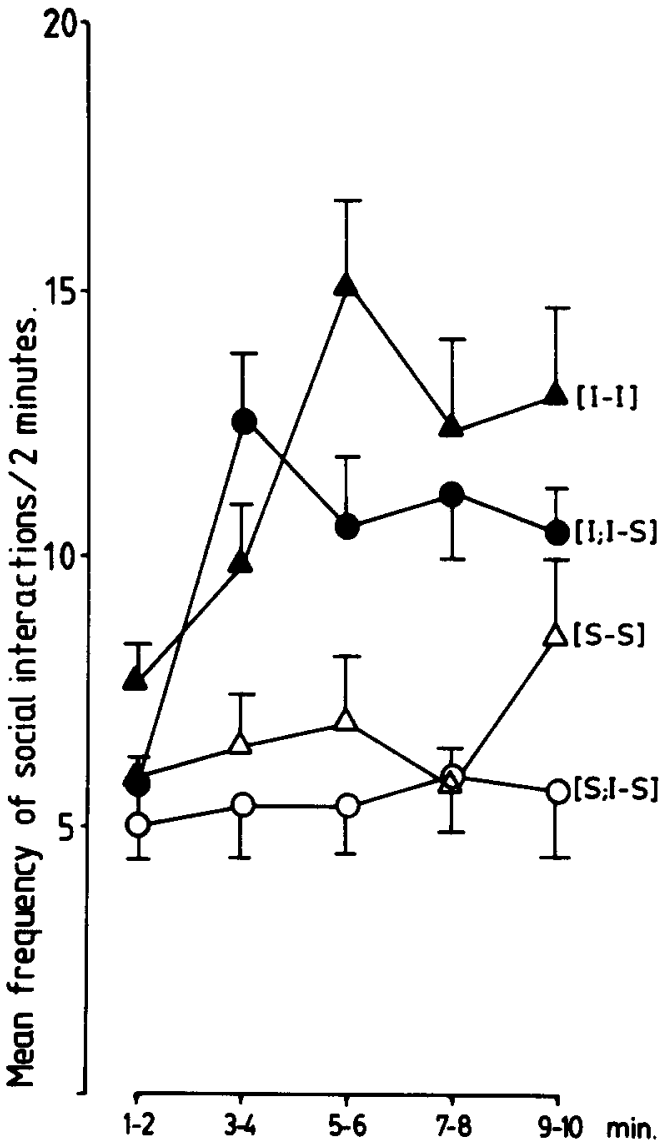

FIG. 2. Frequency of social interactions per 2 minutes. Filled symbols indicate 7-day isolated animals (I), open symbols group-housed animals (S). Rats were tested in pairs with a partner with same housing background (I-I or S-S) $(\Lambda, \Delta)$ or with a partner of different housing background (I-S) $(0,0)$. Data of 12 observations are given as mean score versus time of testing, vertical bars indicate S.E.M.

tion partner/anogenital investigation was not significantly increased in 4 week old rats after 7 days of isolation.

\section{DISCUSSION}

The present experiments show that frequencies of social interactions are increased in short-term isolated rats as com-

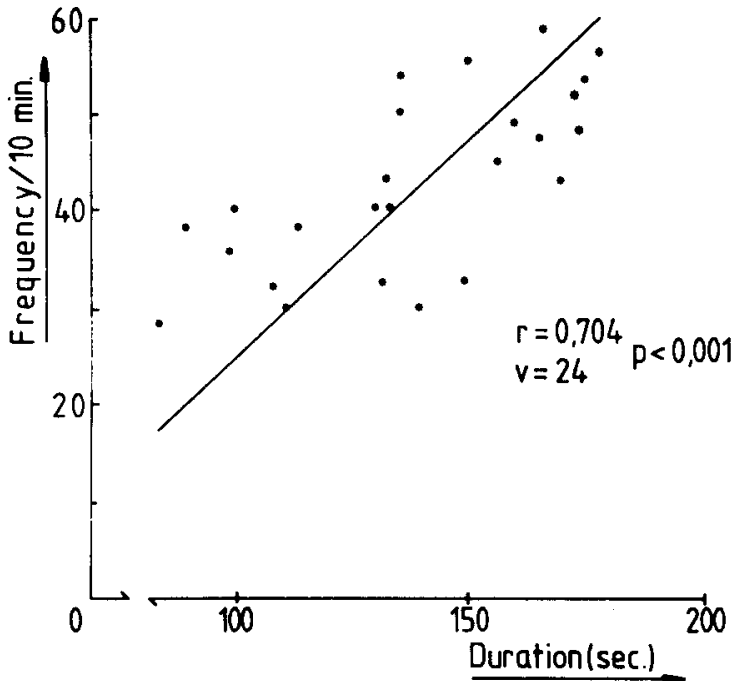

FIG. 3. Correlation diagram comparing frequency and duration (sec) of social interactions of 7-day isolated rats tested with a grouphoused rat $(n=25)$.

pared to group-housed animals, when the rats are put back in a situation with a conspecific. No obvious differences between 7-day isolated and group-housed animals were found in locomotor activities nor in general exploratory behaviors when testing was performed in an open field, and ambulations were scored per 5 minutes. Consistently, Gentsch et al. [14] reported no differences in ambulation between 7-day individual housed and group-housed rats. Although an increase in ambulation during the social interaction test was observed between isolated and group-housed rats, when they were tested with a conspecific of a similar housing background, no difference in ambulation was present when an isolated rat was tested with a group-housed partner. Thus the increase in social activity is a specific increase in gregariousness and not due to a general hyperactivity of the isolated animals, as is reported to occur after prolonged isolation although this response has been questioned $[5,6,13,14,30]$. The duration of the isolation period therefore may be important for changes in locomotor activities (see also [28]). Another variable that should be taken in account is the age of the animals at the onset of the isolation period, since differences were observed between social behavior of rats isolated

TABLE 2

SOCIAL INTERACTIONS OF GROUP-HOUSED (S) AND OF 4-DAY ISOLATED (I) ANIMALS UNDER 3 DIFFERENT TEST CONDITIONS

\begin{tabular}{lcccc}
\hline Time of Testing & Light & $\begin{array}{c}\text { S-S } \\
(8)\end{array}$ & $\begin{array}{c}\text { S-I } \\
(2 \times 5)\end{array}$ & $\begin{array}{c}\text { I-I } \\
(8)\end{array}$ \\
\hline & & & & \\
9:00 a.m.-1:00 p.m. & white & $21.3 \pm 3.5^{*}$ & $16.8 \pm 5.8-37.8 \pm 7.8$ & $35.6 \pm 4.1$ \\
9:00 a.m.-1:00 p.m. & red & $28.9 \pm 2.1$ & $21.0 \pm 1.1-36.3 \pm 3.0$ & $34.9 \pm 2.3$ \\
7:00 p.m.-10:30 p.m. & red & $32.4 \pm 3.9$ & $31.2 \pm 2.9-44.0 \pm 4.6$ & $36.1 \pm 3.6$ \\
& & $F=3.05$ & $(\Delta \mathrm{I}-\mathrm{S}) \mathrm{F}(1,24)=29.77, p<0.001$ & $\mathrm{~F}=\mathbf{0 . 0 4}$ \\
& & n.s. & (cond). $\mathrm{F}(2,24)=4.68, p<0.025$ & n.s. \\
& & & &
\end{tabular}

Tested were S-S, S-I and I-I groups.

Statistical analysis was performed using a two way analysis of variance [25] for the S-I and one way analysis of variance for S-S and I-I groups.

Numbers in parentheses refer to the number of animals in each group.

*Mean \pm SEM. 
TABLE 3

EFFECT OF HABITUATION ON SOCIAL INTERACTIONS

\begin{tabular}{llcl}
\hline Test Pairs & & \multicolumn{1}{c}{ S-I } & $\begin{array}{c}p \text {-value } \\
\Delta I-S\end{array}$ \\
\hline$S_{\text {hab }}$ & $-I_{\text {hab }}$ & $22.6 \pm 2.6-44.6 \pm 2.5$ & $<0.001$ \\
$S_{\text {non-hab }}$ & $-I_{\text {non-hab }}$ & $22.0 \pm 2.0-47.8 \pm 8.2$ & $<0.01$ \\
$S_{\text {non-hab }}$ & $-I_{\text {hab }}$ & $17.2 \pm 2.9-57.0 \pm 9.5$ & $<0.01$ \\
$S_{\text {hab }}$ & $-I_{\text {non-hab }}$ & $29.0 \pm 0.5-48.6 \pm 8.5$ & $<0.05$ \\
\hline
\end{tabular}

Mean social interactions \pm S.E.M. of pairs $(n=2 \times 6)$ of 7-day isolated (I) and group-housed (S) rats.

Animals were habituated to the test cage (hab) or not (non-hab) on the 2 days prior to experimentation.

Tested were I-S pairs.

Statistical analysis was performed by two way analysis of variance.

at 4 weeks and that of rats isolated at 8 weeks after birth (see also [3]).

The difference in social activities between isolated and group housed rats reached a maximum after 4 to 7 days of isolation; repeated testing with the same test partner decreased this enhancement. A few other studies have shown that short term isolation increased social interattraction of rats in dyadic encounters but this effect was apparent only after repeated testing because habituation to the test cage interfered with social interactions $[18,24]$. This apparent discrepancy may be due to different test methods i.e., measuring interindividual distances instead of frequencies. Open field experiments showed more ambulations of I-animals than S-animals during the 2 nd and 3rd minute of the first trial; the sharp decline in ambulation of the S-animals from the first to the 2nd minute during the first trial is observed during the second trial in the I-animals. This could indicate a delayed habituation of I-animals to novel environments. Einon and Morgan [7] claimed a slower habituation to contacts with objects in the open field of isolated animals, but File [10] reported that a general impairment in the ability to habituate is not a characteristic of isolates. However, differences in habituation to the testcage in individually and group-housed animals have been described in mice $[1,15]$. As
TABLE 4

SOCIAL INTERACTIONS AS RELATED TO DURATION OF SOCIAL DEPRIVATION

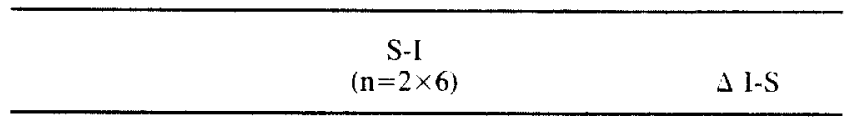

a. Isolation

Period 1-day

1-day

4-days

$25.3 \pm 3.8-36.2 \pm 4.6$

$16.2 \pm 1.7-39.2 \pm 3.6$

10.9 n.s.

7-days

$22.7 \pm 2.6-49.0 \pm 1.5$

$23.0 p<0.001$

28-days

$26.0 \pm 3.0-51.4 \pm 4.2$

$26.3 p<0.001$

$\mathrm{F}(1,40)=80.98 p<0.001^{*}$

$25.4 p<0.001$

$\mathbf{F}(3,40)=5.73 p<0.005 \dagger$

b. Day of

Testing

day 7

day 8

$22.7 \pm 2.6-49.0 \pm 1.5$

$22.3 \pm 3.8-41.3 \pm 7.2$

day 9

$18.7 \pm 2.0-28.0 \pm 3.8$

$26.3 p<0.001$

$19.0 p<0.05$

$\begin{array}{cr}\text { (S) } \mathrm{F}=0.56 & \text { (I) } \mathrm{F}=5.05 \\ \text { n.s. } & p<0.05\end{array}$

9.3 n.s.

$$
p<0.05
$$

a. Mean social interactions ( \pm S.E.M.) of group-housed (S) and isolated (I) rats after different periods of social isolation of the isolated rats. Testing was done in 10 minute I-S encounters. * F value for difference between $I$ and $S$ animals; $\nmid F$ value for differences between isolation periods.

b. Idem after repeated testing with the same partner on days 8 and 9. Statistical analysis was performed using two-way analyses of variance and Student $t$-tests ( $\mathrm{n}=$ number of animals).

far as social interactions are concerned, a habituation effect during the 10-minute test period was not present in our experiment. In fact an increase in social interactions was observed in the I-animals, while no change over time was present in the S-rats. Also habituation to the test cage hardly affected the social interactions. Thus delayed habituation may not be an important factor in the effect of isolation on social interaction as measured under the present test conditions.

Information about the causal factors or the underlying mechanisms of the increase in social behavior of the single

TABLE 5

EFFECT OF 7-DAY ISOLATION ON SOCIAL INTERACTIONS OF ANIMALS AT 4 AND 8 WEEKS AFTER BIRTH

\begin{tabular}{|c|c|c|c|c|c|c|c|c|}
\hline \multirow{2}{*}{$\begin{array}{l}\text { Behavioral } \\
\text { Item }\end{array}$} & \multicolumn{4}{|c|}{ Animals 4 Weeks Old } & \multicolumn{4}{|c|}{ Animals 8 Weeks Old } \\
\hline & & S-I & $\Delta \mathrm{I}-\mathrm{S}$ & $p$-values & & S-I & $\Delta \mathrm{I}-\mathrm{S}$ & $p$-values \\
\hline $\begin{array}{l}\text { Exploration partner/ } \\
\text { Anogenital } \\
\text { investigation }\end{array}$ & $21.3 \pm 1.4$ & $-26.3 \pm 2.2$ & 5.0 & n.s. & $15.2 \pm 1.1$ & $-27.8 \pm 2.4$ & 12.6 & $p<0.001$ \\
\hline $\begin{array}{l}\text { Mounting/ } \\
\text { Social Grooming }\end{array}$ & $14.3 \pm 2.1$ & $-25.0 \pm 3.6$ & 10.7 & $p<0.05$ & $4.7 \pm 1.3$ & $-18.8 \pm 3.5$ & 14.1 & $p<0.01$ \\
\hline $\begin{array}{l}\text { Following/ } \\
\text { Approach }\end{array}$ & $4.5 \pm 0.9$ & $-4.2 \pm 0.4$ & -0.3 & n.s. & $1.8 \pm 0.7$ & $-2.3 \pm 0.7$ & 0.5 & n.s. \\
\hline Kicking & $0.3 \pm 0.2$ & 0 & -0.3 & n.s. & $1.0 \pm 0.8$ & 0 & -1.0 & n.s. \\
\hline $\begin{array}{l}\text { Total Amount of } \\
\text { Social Interactions }\end{array}$ & $40.5 \pm 2.2$ & $55.5 \pm 3.7$ & 15.0 & $p<0.01$ & $22.8 \pm 2.6$ & $-49.0 \pm 1.5$ & 26.2 & $p<0.001$ \\
\hline
\end{tabular}

Tested were pairs of one group-housed (S) and one isolated (I) animal during 10 minutes. Differences were tested with Student's $t$-test. In both groups 6 pairs were tested. 
housed rats is not available as yet, although social deprivation likely is an important factor and endorphins, e.g., have been implicated in social interactions $[9,22,23]$. The hierarchic status in the group seems to be less important in this respect, since the group-housed rats were randomly selected as partner for the isolated rats.

A fairly good correlation between frequency of social interactions and time spent in social contact of the isolated animals was observed. Thus the present procedure is very well comparable with experiments measuring interaction time. However, the present procedure yields more information about qualitative aspects of the isolated animals' behavior.

In conclusion, the present model is very sensitive, re- producible in a rather small group of animals, the behavioral changes are apparent already after a short period of isolation and extinction of the isolation effect can be investigated. Of particular interest is the test situation in which an isolated rat is tested with a group-housed conspecific, because then little if any aggressive like behavior occurs, and the rate of ambulation of the rats hardly differ. The method thus seems very promising for further studies on the effect of short-term isolation in rats.

\section{ACKNOWLEDGEMENT}

We thank Emilie Bloemarts for her skillful technical assistance.

\section{REFERENCES}

1. Benton, D. and P. F. Brain. Behavioral and adrenocortical reactivity in female mice following individual or group housing. Devl Psychobiol. 14: 101-107, 1981.

2. Brain, P. F. What does individual housing mean to a mouse? Life Sci. 16: 187-200, 1975.

3. Brain, P. F. and D. Benton. What does individual housing mean to a researchworker? IRCS Med. Sci. 5: 459-463, 1977.

4. Brain, P. F. and D. Benton. The interpretation of physiological correlates of differential housing in laboratory rats. Life Sci. 24: 99-116, 1979.

5. Dalrymple-Alford, J. C. and D. Benton. Activity differences of individually and group-housed male and female rats. Anim. Learn. Behav. 9: 50-55, 1981.

6. Dalrymple-Alford, J. C. and D. Benton. The effect of social isolation of the rat on open field activity and emergence. Behav. Processes 6: 283-290, 1981.

7. Einon, D. F. and M. J. Morgan. A critical period for social isolation in the rat. Devl Psychobiol. 10: 123-132, 1977.

8. Elliot, O. and J. P. Scott. The development of emotional distress reactions to separations in puppies. J. genet. Psychol. 99. 3-22, 1961.

9. File, S. E. Naloxone reduces social and exploratory activity in the rat. Psychopharmacology 71: 41-44, 1980.

10. File, S. E. Exploration, distraction and habituation in rats reared in isolation. Devl Psychobiol. 11: 73-81, 1978.

11. File, S. E. and J. H. Pope. Social interaction between drugged and undrugged rats. Anim. Learn. Behav. 2: 161-164, 1974.

12. Gardiner, S. M. and T. Bennett. The effect of short-term isolation on systolic blood pressure and heart rate in rats. Med. Biol. 55: 325-329, 1977.

13. Garzón, J., J. A. Fuentes and J. del Rio. Antidepressants selectively antagonize the hyperactivity induced in rats by long term isolation. Eur. J. Pharmac. 59: 293-296, 1979.

14. Gentsch, C., M. Lichtsteiner, K. Kraeuchi and H. Feer. Different reaction patterns in individually and socially reared rats during exposures to novel environments. Behavl Brain Res. 4: 45-54, 1982.

15. Goldsmith, J. F., P. F. Brain and D. Benton. Effects of the duration of individual or group housing on behavioural and adrenocortical reactivity in male mice. Physiol. Behav. 21: 757760,1978

16. Grant, A. C. An analysis of the social behavior of the male laboratory rat. Behaviour 21: 260-283, 1963.

17. Hansen, S. Mounting behavior and receptive behavior in developing female rats and the effect of social isolation. Physiol. Behav. 19: 749-752, 1978.

18. Harkins, S., L. A. Becker and D. C. Wright. Gregariousness and aggression in wild and domestic rats. Bull. Psychon. Soc. 4: $119-122,1974$.
19. Harlow, H. F. and M. K. Harlow. Social deprivation in monkeys. Scient. Am. 207: 136-147, 1962.

20. Latané, B., H. Cappell and V. Joy. Social deprivation, housing density and gregariousness in rats. J. comp. physiol. Psychol. 70: 221-227, 1970.

21. Lovely, R. H., R. R. Paganano and R. M. Paolina. Shuttle box avoidance performance and basal corticosterone levels as a function of duration of individual housing in rats. J. comp. physiol. Psychol. 81: 331-335, 1972.

22. Panksepp, J. Brief social isolation, pain responsivity and morphine analgesia in young rats. Psychopharmacology 72: 111$112,1980$.

23. Panksepp, J. and P. Bishop. An autoradiographic map of ${ }^{3} \mathrm{H}$ diprenorphine binding in rat brain: effects of social interaction. Brain Res. Bull. 7: 405-410, 1981.

24. Popalawsky, A., D. A. Johnson and D. Popalawsky. Quantitative and qualitative measures of open field social behavior in the rat. Bull. Psychon. Soc. 3: 360-362, 1974.

25. Rohlf, F. J. Two way ANOVA with replications. In: Biometry, 2nd edition, edited by R. R. Sokal and F. J. Rohlf. San Francisco: W. H. Freeman, 1969.

26. Shapiro, S. S. and M. B. Wilk. An analysis of variance test for normality. Biometrika 52: 591-611, 1965.

27. Thoa, N. B., Y. Tizahi and D. M. Jacobowitz. The effect of isolation on catecholamine concentration and turnover in discrete brain areas of the rat brain. Brain Res. 131: 259-269, 1977.

28. Timmermans, P. J. A. Social behaviour in the rat. Unpublished thesis, Nijmegen, The Netherlands, 1978.

29. Valzelli, L. Aggressive behaviour induced by isolation. In: Aggressive Behaviour, edited by S. Garattini and E. B. Sigg. Amsterdam: Excerpta Medica, 1969, pp. 70-76.

30. Valzelli, $\mathbf{L}$. Social experience as a determinant of normal behavior and drug effect. In: Handbook of Psychopharmacology, edited by L. L. Iverson, S. D. Iverson and S. H. Snyder. New York: Plenum Publishing, 1977.

31. Weinstock, M. and Z. Speiser. The effect of dl-propanolol, d-propanolol and practolol on the hyperactivity induced in rats by prolonged isolation. Psychopharmacologia 30: 241-250, 1973.

32. Welch, B. L., D. G. Brown, A. S. Welch and D. C. Lin. Isolation restrictive confinement or crowding of rats for one year. I. Weight, nucleic acids and protein of brain regions. Brain Res. 75: 71-84, 1974.

33. Weynen, J. A. W. M. and J. L. Slangen. Effects of ACTHanalogues on extinction of conditional behavior. In: Progress in Brain Research, vol. 32, edited by D. De Wied and J. A. W. M. Weynen. Amsterdam: Elsevier, 1970. 